\title{
Alunos e professores no Orkut: a educação escolar na arena ciberespacial
}

\author{
Alessandro Eleutério de Oliveira \\ Antônio Álvaro Soares Zuin \\ Universidade Federal de São Carlos
}

\section{Resumo}

O objetivo deste artigo consiste em investigar as comunidades virtuais da Internet dedicadas à educação escolar. Assim, analisamos manifestações escritas de professores e alunos a fim de apreendermos as maneiras como os sujeitos envolvidos no processo ensino-aprendizagem percebem uns aos outros. As lucubrações são iluminadas por autores da Teoria Crítica como Theodor Adorno e Walter Benjamin, por meio da confluência do material coletado nas comunidades virtuais com temas como desorientação, fragmentação e semiformação na contemporaneidade e os seus reflexos na educação escolar brasileira.

Palavras-chave: Experiência. Comunidades virtuais. Educação escolar. 


\section{Students and teachers on Orkut: school education in the cyber arena}

This article aims at analyzing virtual communities about school education. Therefore, we scrutinize manifestations written by teachers and pupils in order to understand the ways in which people involved in the teaching-learning process perceive one another. Our lucubration is illuminated by Critical Theory authors such as Theodor Adorno and Walter Benjamin, by means of the confluence of the collected material in the virtual communities with topics like disorientation, fragmentation and half-formation in contemporaneity, and its reflections on Brazilian school education.

Keywords: Experience. Virtual communities. School education.

\section{Estudiantes y profesores en Orkut : la educación escolar en el ámbito cibernético}

El objetivo de este trabajo es analizar las comunidades virtuales de Internet dedicadas a la educación escolar. Por lo tanto, se analizaron las declaraciones escritas de los profesores y los estudiantes con la intención de comprender las formas en que las personas involucradas en el proceso enseñanza-aprendizaje se perciben mutuamente. Las reflexiones son iluminadas por los autores de la teoría crítica, como Theodor Adorno y Walter Benjamin, por la confluencia de los materiales recogidos en las comunidades virtuales con temas tales como la desorientación y la fragmentación así como la semiformación en la sociedad contemporánea y sus reflejos en la educación escolar en Brasil.

Palabras clave: Experiencia. Las comunidades virtuales. La educación escolar. 


\section{As transmudações da experiência e das formas comunicacionais e agregacionais}

Em um famoso ensaio denominado Experiência e Pobreza, publicado em 1933, o teórico crítico Walter Benjamin (1996) evidenciava a importância da narração de experiências alicerçadas nos fluxos de vida para a constituição dos sujeitos, sobretudo quando eram transmitidas pelos idosos, receptáculos privilegiados e, por isso, essenciais para a manutenção dos nexos socioculturais pautados na tradição oral. Benjamin contava a história de um pai agonizante que enigmaticamente dizia aos seus filhos que sob os vinhedos da família encontravam-se grandes riquezas. Após a agonia do progenitor, os filhos rasgaram o solo em busca do prometido tesouro. Dado o fracasso de tal intento, os herdeiros não conseguiram compreender as últimas palavras do patriarca até a chegada do outono, quando as videiras frutificaram de modo espetacular. Somente então ocorreu o entendimento do ensinamento paterno, na medida em que eles perceberam que a felicidade decorria do trabalho do sujeito. Nesse caminho, segundo Benjamin, a herança metafórica era constituída por uma experiência engendrada e comunicada de uma geração para outra subsequente.

Experiência. Eis um conceito fundamental para a compreensão das vicissitudes historicamente edificadas que conceberam a condição humana no mundo hodierno. Segundo Benjamin, a ideia de experiência (Erfahrung em alemão) está inserida no domínio da tradição construída por meio de uma confluência entre a esfera pública e a esfera pessoal (Benjamin, 1994, p. 105). Dessa forma, “onde há experiência no sentido estrito do termo, entram em conjunção, na memória, certos conteúdos do passado individual com outros coletivos" (Benjamin, 1994, p. 107). Nesse caminho, em outro emblemático texto de Benjamin (1996), denominado 0 Narrador - considerações sobre a obra de Nikolai Lescov (datado de 1936), o frankfurtiano afirmava que nas sociedades artesanais, por intermédio da narração oral experiencial - como é possível perceber pela história do pai moribundo-, efetivava-se a transmissão das memórias, dos ensinamentos ético-morais e dos costumes:

Essa tradição não configura somente uma ordem religiosa ou poética, mas desemboca também, necessariamente, numa prática comum; as histórias do narrador tradicional não são simplesmente ouvidas ou lidas; elas acarretam uma verdadeira formação (Bildung), válida para todos os indivíduos de uma mesma coletividade. (Gagnebin, 1999, p. 57).

Esse processo formativo edificava ao longo dos anos um sentido de coletividade nas comunidades, ou seja, de um sentimento de pertencimento sociocultural que orientava 
as pessoas ao longo de suas existências. Isso acontecia em uma realidade na qual o tempo era aliado da arte de se contar histórias. Assim, a transmissão da Erfahrung pela palavra falada se dava em um panorama macroestrutural que configurava um tempo em que "o tempo não contava" (Benjamin, 1996, p. 206), e, por esse motivo, era assimilado como eterno. Tal forma de apreensão psicossocial da realidade sucedia em correlação com o modo de produção pré-capitalista, o qual, por sua vez, se dava por meio do trabatho manual em um mundo predominantemente agrário.

Essa dimensão social, cultural e temporal sofreu um abalo avassalador com a ascensão da burguesia industrial, que impôs ao mundo o modo de produção capitalista, o qual desconjuntou e interseccionou a dimensão temporal eterna. 0 tempo passou a ser constituído por uma infinidade de instantes, que passaram a ser medidos, administrados e, dessa maneira, atrelados à dinâmica emergente do encadeamento das forças produtivas que perseguia vorazmente o lucro. Ou seja, a máxima apregoada que se encarna na frase time is money simboliza um processo infraestrutural que expulsa a narrativa experiencial tradicional da existência social, na medida em que esta não agrega em si valor de troca, transformando-se em uma forma comunicacional obsoleta e alienígena que nada tem a dizer em um mundo regido pelo ritmo frenético das engrenagens industriais. Dessa forma, a experiência tradicional - Erfahrung - cedeu lugar nas sociedades capitalistas à Erlebnis, que seria a vivência do indivíduo atomizado, desenraizado e desorientado (Gagnebin, 1994).

Benjamin $(1994,1996)$ afirma que à medida que a burguesia capitalista se solidificava, a fragmentação da tradição oral - alicerce da Erfahrung - encontrou na atomização crescente do indivíduo um receptáculo para a difusão de uma forma de se contar histórias que só se torna possível graças à invenção do poderoso instrumento que serviu como propagador ideológico desta classe emergente - a imprensa. Nessa conjuntura, os romances escritos proliferaram, de modo que foi construída uma forma acabada, dotada de um sentido pré-definido, de se contar uma história:

A obtenção de uma memória comum, que se transmite de geração em geração, é hoje destruída pela rapidez e violência das transformações da sociedade capitalista. Agora o refúgio da memória é a interioridade do indivíduo, reduzido à sua história privada, tal como ela é reconstruída no romance. (Gagnebin, 1982, p. 68).

Nesse percurso, Benjamin $(1994,1996)$ lembra que ao mesmo tempo em que isso sucedia, outra forma de comunicação também nascia: a informação. Ela também foi beneficiada pela imprensa, e muito mais em termos quantitativos do que a publicação de romances. Essa forma de comunicação em massa se confrontou diretamente com a narração. Ao contrário da narrativa oral tradicional, a informação veiculada pela 
imprensa não tem como objetivo fazer com que o leitor se aproprie de seus dados a fim de que os mesmos possam compor sua experiência. Na verdade, a informação teria como umas de suas principais características a sua efemeridade.

0 avanço da comunicação informacional ocorreu à medida que o modo de produção capitalista diluiu paulatinamente os vínculos socioculturais, de maneira que os diversos aspectos da vida cotidiana foram reificados e atrelados ao frenesi fabril, desferindo, dessa forma, um tiro de misericórdia na experiência tradicional. Nessa direção, é salutar trazer à baila as análises de Benjamin sobre a obra de Charles Baudelaire, o poeta do século XIX que experienciou e descreveu liricamente as profundas transformações decorrentes do processo de urbanização e de industrialização desenfreadas que acometiam uma Paris que se urbanizava vertiginosamente. Por intermédio das lentes benjaminianas, é possível perceber na obra de Baudelaire as inquietações do sujeito em meio à formação dos aglomerados urbanos, nos quais as massas humanas transitam pelos locais de grande circulação e vão se ampliando com as modificações nos sistemas de transporte e nas paisagens das cidades. Desse modo, “a contemplação cede lugar à transitoriedade de impressões e tudo passa a ser incorporado de maneira sistêmica à natureza funcional dos esquematismos da produção e do consumo" (Costa, 2002, p. 67). Assim, é engendrada uma experiência de choque (Schockerlebnis), análoga à vivência do operário fabril:

0 mover-se através do tráfego implicava uma série de choques e colisões de cada indivíduo. Nos cruzamentos perigosos, inervações fazem-no estremecer em rápidas sequências, como descargas de uma bateria. Baudelaire fala do homem (sic) que mergulha na multidão como em um tanque de energia elétrica. E, logo depois, descrevendo a experiência do choque, ele chama esse homem (sic) de um caleidoscópio dotado de consciência. (Benjamin, 1994, p. 124-125).

Essa experiência de choque, portanto, se realiza no cotidiano urbano capitalista não somente em situações como andar por uma calçada abarrotada de transeuntes, em meio a recorrentes esbarrões e cotoveladas, mas também em situações de recepção de produtos midiáticos que corroboram a naturalização dessa forma de socialização no aparato psicossensorial. Nessa direção, isso pode ser vivenciado quando se assiste a um filme (obra que amalgama som, imagem e movimento), já que nele "a percepção sob a forma de choque se impõe como princípio formal" de modo que "aquilo que determina o ritmo da produção na esteira rolante está subjacente ao ritmo da receptividade, no filme" (Benjamin, 1994, p. 125). Esse tipo de experiência paulatinamente se expande através do surgimento dos parques de diversão - como o Luna Park observado por Benjamin - e, posteriormente, por meio da televisão e do vídeo games, 
entre outros meios de comunicação para as massas, que se unem paulatinamente àqueles anteriormente destilados da imprensa como os romances e os jornais.

Posto isso, o/a ledor/a pode inferir que Benjamin lamentava a perda de uma narrativa oral tradicional que congregava idilicamente os sujeitos no mundo pré-capitalista. Ora, sabemos que as sociedades artesanais eram marcadas pela impermeabilidade social, por epidemias devastadoras e pelo obscurantismo. Na verdade, o teórico crítico teria oferecido em seus escritos pistas para uma nova narrativa experiencial que seria efetivada na modernidade, diferentemente daquela que se dava no campo da tradição oral (Gagnebin, 1999). Pensamos que essas novas formas de narratividade possam se dar - mesmo em um contexto em que o mundo é vivenciado por meio de choques imagéticos - em novos lócus de afluência social que travestem e ressignificam aceleradamente as formas comunicacionais e agregacionais.

\section{Forças simbólicas colapsadas e intentos de adsorção}

O aparecimento e a paulatina consolidação do modo de produção capitalista, juntamente com a sua representação superestrutural que seria a modernidade, fez com que a própria ideia de moderno esteja atrelada a um ritmo de aceleração desenfreado. A efetivação do ser moderno não se esgota em si enquanto efetivação concreta de modos de se pensar e agir sobre si e sobre o mundo, mas se dá insaciavelmente em meio a um turbilhão de modernidade (Le Goff, 2003, p. 2004). Turbilhão este que se torna cada vez mais emaranhado e convulso na primeira década do século XXI.

As implicações da dominação psicossocial levada a cabo pelos meios de comunicação para as massas em meio às utopias dos mercados livres e da globalização - que retroalimentam esse turbilhão - encarnam-se em questões que vão de e ao encontro das contradições sociais, econômicas, políticas e culturais que corroboram a sensação de se viver em uma realidade fragmentada, cujas significações se perdem entre as suas múltiplas fraturas (Dupas, 2001, p. 49).

Em um mundo no qual as novas tecnologias engendram produtos de consumo inéditos, em meio a ondas de arroubo que se sustentam e se projetam instantaneamente por obra do aparato midiático, o processo de experienciação através dos choques imagéticos é ininterruptamente reforçado. Nesse panorama, o telefone celular e a internet, símbolos da interconectividade, são condições essenciais para a felicidade consumista, na qual a projeção de uma imagem de êxito pessoal segue os ditames que emanam do arquétipo totêmico - que encarna todas as virtudes do sujeito hodierno construído pelo mass media, como Adorno e Horkheimer (2006) já haviam percebido 
no final da década de 1940 nos escritos que compõem a Dialética do Esclarecimento Ino texto A Indústria Cultural: o Esclarecimento como Mistificação das Massas e em algumas notas e esboços). Isso acontece no seio da Indústria Cultural, ou seja, da

[...] produção em série da cultura, ainda que em um primeiro momento aparecesse como uma forma cultural das massas. É importante enfatizar que a crítica que dirigem à Indústria Cultural está inscrita na preocupação com a paralisia do iluminismo, pelo modo através do qual as sociedades haviam arruinado seu "potencial emancipador". (Jay, 1988 apud Leoraduzzi; Gerzovich; Entel, 2008, p. 28, tradução nossa).

Dessa forma, a Indústria Cultural efetiva e corrobora um processo de antiemancipação da consciência e da autonomia individuais, o que faz com que a subjetividade individual seja capturada e modelada pelos meios de comunicação para as massas, sujeitando-a a uma totalidade social, o que culmina em uma "subjetividade coletiva e homogênea" (Formoso; Batista, 2002, p. 27). Dessa forma, “o mundo inteiro é forçado a passar pelo filtro da Indústria Cultural" (Adorno; Horkheimer, 2006, p. 104).

Esse processo - por meio dos quais os sujeitos atomizados, desenraizados e desorientados são orientados pela indústria cultural - resulta em uma semiformação, que nada mais é que o espírito conquistado pela lógica do fetiche da mercadoria, o que implica na reprodução de conscientes coisificados, padronizados e afeitos ao dado imediato, e, por essa razão, destituídos de uma relação histórica com o mesmo. Trata-se, portanto, de uma formação cultural lesada que faz com que as pessoas estabeleçam relações socioculturais de modo alienado, ou seja, sem que se desenvolvam como sujeitos autônomos capazes de compreender e atuar criticamente sobre a realidade na qual estão imersas (Adorno, 2010).

Nesse contexto, Debord (1997) afirma que, se na primeira fase de cooptação da vida social pela existência mercadológica, ocorreu uma degradação do ideário existencial do ser para ter, nas últimas décadas a vida social tem sido arrebatada totalmente pelos resultados acumulados pelo campo econômico. Isso acarretou um deslizamento do "ter" para parecer ter. 0 quadro se tornou mais complexo à medida que o sujeito do mundo hodierno torna-se cada vez mais performático, vivenciando o momento, e buscando com sofreguidão o êxtase efêmero e superficial (Birman, 1998 apud Dupas, 2001, p. 53).

Melman (2008), por sua vez, percebe a atomização, o consumismo desenfreado e a perda da tradição - que adquirem uma magnitude inédita no início do século XXI imiscuídos na emergência do que ele denomina uma nova economia psíquica. Para o psicanalista lacaniano, trata-se de uma mutação cultural que traz em seu cerne novas formas de pensar, julgar, ter relações sexuais, de vivenciar a família, a pátria, os ideais e, nessa direção, a própria existência social como um todo. Essa reconfiguração psíquica 
global - ou ao menos nas áreas de influência ocidental - seria inédita, fazendo com que o plano psíquico passe de uma economia aparelhada pelo recalque para uma economia organizada pela exibição do gozo. Se Melman vê novos problemas psiquiátricos à espreita, por outro lado, vê um lado progressista - e até mesmo libertário - nessa mudança, pelo fato de as pessoas se darem conta cada vez de que o "céu está vazio tanto de Deus quanto de ideologias" (Melman, 2008, p. 16). Nessa conjunção, os avanços científicos romperam os últimos elos tradicionais com os outrora mistérios da vida e da morte. Assim, a intervenção humana decisiva teria sido o domínio da fecundidade e, posteriormente, da reprodução da vida. Como outro aspecto e simultaneamente desdobramento dessa pulverização do sagrado, o estudioso relembrou uma famosa exibição de cadáveres escorchados conservados em acetona, de modo que se pudessem impor-lhes posturas próximas das da vida. Esta exposição recebeu em Bruxelas o título de 0 fascínio do autêntico, e passou por várias cidades europeias. Esta amostra foi experienciada pelo estudioso, que ali percebeu um xeque-mate sobre a sacralidade do próprio corpo humano, que agora serve a enleios estéticos necrofílicos lou de necroscopia, como quer Melman).

Esse processo engendraria, portanto, “sujeitos flexíveis e perfeitamente capazes de se modificar, de se deslocar, de mudar, de empreender carreiras ou experiências diversas" (Melman, 2008, p. 39). Um reflexo dessa transformação estaria na nossa relação com o sexo, que seria cada vez mais abstraído de seus aspectos simbólicos, e por essa razão, estaria cada vez mais instrumentalizado. Ou seja, o sexo estaria passando por um processo de objetivação de modo que a sua efetivação - enquanto ato sexual constituiria apenas um fim em si mesmo, por meio de um hedonismo vazio assentado em uma perversão generalizada. Dessa forma, de acordo com Melman, deslocamos o eixo relacional com o sexo da representação outrora familiar por sua presentação, e "assim, o sexo é encarado como uma necessidade, como a fome ou a sede, agora que estão suspensos tanto o limite quanto a distância próprios do sagrado que o albergava" (Melman, 2008, p. 20). Ou ainda, segundo Lastória,

Em termos lacanianos estaríamos regredindo de um ordenamento cultural estruturado a partir do falo como instância simbólica representante do pênis em direção ao pênis propriamente dito, exibido agora sem nenhum tipo de escrúpulo por uma linguagem predominantemente icônica. Melman sublinha ainda que o fim de uma cultura fundada na representação implicaria, igualmente, a impossibilidade de relações transferenciais, o que, por sua vez, coloca em xeque o próprio setting do tratamento psicanalítico. (Lastória, 2008, p.66).

Nessa orientação, no processo de substituição da representação pela presentação sucede a configuração de uma linguagem iconográfica que se realiza impavidamente 
na Internet, de forma que ali se substitui a verbalização pela imagem. Isso se dá em meio à profusão de abalroamentos imagéticos que ocorrem por meio de meros cliques no mouse de um computador, o que leva a Schockerlebnis a uma amplitude colossal. Assim, se não há laços sociais fortes e permanentes, se não existe um ponto gravitacional simbólico no qual possamos nos adsorver, as tentativas de estabelecimentos de elos, mesmo que estes sejam fugidios, continuam a ser garatujadas. Pode-se, sob esse prisma, se questionar sobre os modos pelos quais esse sujeito sem gravidade intenta se aderir ao real. Se tal questão possui desdobramentos filosóficos, psicológicos, antropológicos e sociológicos que precisam ser detida e lucidamente debatidos, podemos inferir que há tentativas de adesão. Entretanto, tais intentos estariam circunscritos à necessidade de se

[...] compartilhar de uma paixão comum que chega, nos dias de hoje, a juntá-las em comunidades, reduzidas assim ao nível dos clubes, ao acaso; os motoqueiros, os ecologistas, os caçadores, os patriotas, os homossexuais, etc; e a arte de governar se transformou na de tornar compatíveis entre si e com as diretivas bruxelenses os interesses opostos de grupos de pressão. (Melman, 2008, p. 191).

Nesse sentido, é profícuo nos remetermos ao conceito de rede registrado por Castells, que constituiria o receptáculo da organização das funções e dos processos dominantes na era da informação. As redes seriam um conjunto de nós interconectados. Os nós, por sua vez, seriam os pontos nos quais uma ou mais curvas ou fluxos se encontram. Desse modo, são redes os fluxos financeiros planetários; a teia de relações políticoinstitucionais que regem a União Europeia; o tráfico de entorpecentes que comanda parcelas de economias, sociedades e Estados em todo o mundo; a rede global de novas mídias, que define a essência da expressão cultural e da opinião pública, como a Internet. Elas formariam a nova morfologia social de nossas sociedades, de modo que a propagação de sua lógica altera fortemente a operação e os resultados dos processos de produção material e simbólica da humanidade. Dessa forma, o poder desloca-se para quem tem o controle dos fluxos. Ou seja, ordenar uma rede, estar presente nela e operar a dinâmica de sua interrelação com outras redes define as estruturas de dominação e de transformação de nossa sociedade (Castells, 1998 apud Dupas, 2001, p. 42).

Nessa acepção, em uma obra matricial para o entendimento de novas formas comunicacionais e agregacionais que emergem na Internet, Türche (2010) afirma que vivemos em um momento sociocultural que gera uma compulsão profunda e generalizada para a emissão de nossa presença etérea - contraparte imagética de nossa presença física - na rede ciberespacial. Dessa maneira, de acordo com a lei básica da nova ontologia, a emissão torna possível ser percebido, o que na contemporaneidade 
torna-se sinônimo de ser. Por sua vez, a não emissão acarreta o não ser, a despeito da permanência da presença física do sujeito fora da irradiação midiática, que se vê reduzido a um mero resíduo vivo. Ou ainda, segundo Le Breton (2003), o corpo deixa de ser uma fronteira identitária, passando a constituir mero vestígio deixado no espaço, de modo que

0 viajante da infoesfera não se sente mais preso a um corpo físico. Ele conduz sucessivas explorações sob identidades geralmente diferentes, em um mundo imaterial [...] Seu corpo físico, comparado a seus múltiplos corpos virtuais, não é senão uma prisão, uma necessidade antropológica, que de bom grado dispensaria. 0 corpo eletrônico atinge a perfeição, imune à doença, à morte, à deficiência física. (Le Breton, 2003, p. 124).

Em relação a esse ponto de inflexão identitária, Feenberg (2003) afirma que o sujeito que utiliza a web para se socializar no fluxo imagético por meio do computador é percebido como um usuário, ou seja, como uma pessoa envolvida em um novo tipo de atividade social que não se limita ao papel de mero consumidor em meio a um conjunto de opções enlatadas, mas potencializa a partir dessa forma horizontalizada de intercâmbio informacional a construção de um modelo comunicacional democrático.

Apesar desse potencial, se por um lado a web efetiva uma conectividade maior entre pessoas de todo o globo, Bauman (2004) afirma que o outro lado da moeda da proximidade virtual seria a distância virtual. Isso quer dizer que sucede a suspensão, e até mesmo a anulação, de qualquer coisa que transforme a contiguidade topográfica em proximidade. Nessa acepção, "a proximidade não exige mais a contiguidade física; e simultaneamente, a contigüidade física não determina mais a proximidade" (Bauman, 2004, p. 81). Apesar disso, grandes são os atrativos da Internet para os sujeitos atomizados, flexíveis, a buscarem lampejos de eternidade em gozos efêmeros. Na rede virtual, pode-se correr em busca de abrigo quando a multidão urbana oferece desconforto e perigos objetivos e subjetivos. Por graça dela, pode-se conversar, namorar e obter sexo casual - presencial ou não - de acordo com a comodidade de cada indivíduo. Assim, a web constitui o lócus virtual por meio do qual os sujeitos procuram estabelecer elos, mesmo que estes resultem apenas em laços sociais pobres (Melman, 2008, p. 126).

\section{A Educação Escolar é colocada em xeque na arena ciberespacial}

No atual estágio do encadeamento das forças de produção e reprodução objetiva e subjetiva do sistema capitalista, em meio a políticas públicas para a educação que ainda refletem o ideário neoliberal, a educação é dialeticamente transpassada por aspectos 
libertários e reificadores, refletindo as contradições socioculturais (Zuin, 2003). Ora, a escola é - ou deveria ser - uma das guardiãs das Artes, das Ciências e da Literatura. Nela, o conhecimento historicamente erigido é transmitido e reconstruído à medida que é comunicado pelos mestres aos seus aprendizes, constituindo um espaço de diálogo e, em grande medida, de comunicação oral (Oliveira, 2008). A partir de situações dialogais, essas contradições da existência humana - como percebeu Sócrates há milênios - podem vir à superfície, e podem ser debatidas e perscrutadas em sala de aula. Em relação a essa potencialidade, Ramos-de-Oliveira (1997) relembrou a criação das disciplinas de Educação Moral e Cívica, Organização Social e Política do Brasil e Estudos de Problemas Brasileiros nos ensinos básico e superior em pleno regime militar brasileiro. Essas disciplinas deveriam ajustar as mentes dos alunos aos ditames da tecnoburocracia ditatorial. Se isso ocorreu em grande medida, por outro lado, talvez por falta de legitimidade e abrangência, essas disciplinas constituíram espaços de discussão dos problemas socioexistenciais dos alunos, constituindo "janelas para o mundo" (Ramos-de-Oliveira, 1997, p. 26).

Mas em que medida poder-se-á realizar reflexões e questionamentos autênticos em uma escola cujo alunado é configurado desde a primeira infância por meio do engendramento da semiformação com o amparo ubíquo dos meios de comunicação para as massas? Pois são essas as crianças e jovens que a escola brasileira tem recebido - sujeitos moldados pela Erlebnis levada ao extremo pelo aparato midiático - e procurado educar no sentido de a eles transmitir o conhecimento historicamente construído pelo saber humano. A alienação decorrente da fragmentação dos vínculos sociais e da ação da indústria cultural, a ausência de eixos gravitacionais simbólicos e o culto ao individualismo, aos gozos efêmeros e a novas atitudes de barbárie cotidiana (como o emblemático bullying) permitem de algum modo o reestabelecimento de uma experiência sociocultural direta que possibilitaria o resgate de uma formação plena (no sentido de Bildung) que não estaria circunscrita a alguns setores acadêmicos muito específicos?

Talvez para começar a responder a questões como estas devamos primeiramente entender de que maneiras os sujeitos se orientam em meio à sua desorientação para se narrarem suas experiências contemporâneas que se dão no processo ensinoaprendizagem. Por meio dessas manifestações, podemos obter dados importantes sobre o que alunos e professores pensam acerca da educação, da escola e dos sujeitos que a compõem e, de modo mais amplo, sobre a totalidade da existência social. Pensamos que os reflexos dessa desorientação no ambiente escolar podem ser percebidos em outros espaços de comunicação que não estão na escola - como a sala de aula -, mas que constituem ambientes que tendem a aglutinar coletividades - mesmo que por meio 
de um laço social pobre -, constituindo instâncias essenciais em uma realidade cada vez mais influenciada pela organização em redes. Dessa maneira, esse espaço privilegiado, caótico e coruscante pode contribuir para a compreensão sobre os modos como esses sujeitos se atraem, se rechaçam e se interpretam em um contexto de experiência formativa lesada que culmina em semiformação.

Nesse sentido, Adorno (2001) já havia feito nos anos 1960 uma interessante análise sobre o relacionamento interpessoal entre alunos e professores no texto Tabus acerca do magistério. 0 teórico crítico discorreu sobre como o modelo de personalidade representado pela figura docente - que a priori despertaria no aluno admiração, respeito e afeto, auxiliando no processo de constituição e consolidação de um ego adulto saudável - acaba recorrentemente se tornando uma mola propulsora para sérios problemas relacionais em sala de aula. Essa idealização é frequentemente estilhaçada no cotidiano escolar por meio de situações e atos que decepcionam, frustram e aterrorizam não somente os alunos, como também os professores - em um relacionamento transpassado por uma série de fatores psicossociais historicamente erigidos -, impedindo a realização da relação dialógica, e afastando, dessa forma, os interlocutores encarnados nas figuras no mestre e do pupilo.

Nesse caminho, o estudo das comunidades virtuais - que constituem a versão virtual do local real, e nas quais se reúnem um número crescente de sujeitos em escala global -, pode nos auxiliar a entender como a experiência calcada no processo-aprendizagem é narrada oralmente pelos sujeitos, já que nessas comunidades as pessoas tendem a materializar suas verbalizações em textos escritos que refletem em grande medida a palavra falada, trazendo à tona aspectos objetivos e subjetivos presentes na escola.

Por essa razão, é salutar nos determos no sítio de relacionamentos virtuais Orkut. Trata-se de um ambiente de socialização composto por milhões de pessoas de várias nacionalidades. É um local virtual no qual cada membro da comunidade possui uma conta pessoal e um perfil por meio do qual comunica aos outros internautas características de personalidade como hábitos de leitura, gostos musicais, culinários etc. Se suceder identificação entre as preferências de um determinado usuário, ambos podem se incluir mutuamente enquanto amigos em suas respectivas contas, de modo que gradualmente são formadas as comunidades virtuais. Estas contêm enquetes e fóruns de debate, nos quais inúmeros tópicos são discutidos.

Nesse trajeto, podemos perceber que redes sociais como o Orkut fornecem as condições ideais para realização do indivíduo performático (que projeta a sua imagem); que pode aparentar ter para ser; ser volátil ou flexível ljá que se pode sair de qualquer comunidade ou conta de alguém); permitem também uma consumação catártica, em um gozo coletivo que exterioriza sentimentos ambivalentes sobre sujeitos que desem- 
penham papéis sociais específicos, como os professores; e, principalmente assegura a existência social no local virtual ao internauta, o que o impede de ser relegado a um mero resíduo vivo. Igualmente, permite que novas formas de narratividade que efetivem o compartilhamento de experiências abrolhem no ciberespaço, o que efetiva o intercâmbio de experiências de toda ordem, inclusive aquelas que se originam no lócus escolar.

Nessas comunidades virtuais, o processo que transforma representação em presentação é evidenciado pela iconografização da linguagem e pode ser observado de forma privilegiada. Isso sucede ora por meio da escrita de frases eloquentes e raivosas apenas em letras maiúsculas, ora pelo uso de termos aparentemente indizíveis através do uso de caracteres juntados em frases sem sentido aparente que, no entanto, também podem demonstrar os sentimentos e ideias que alicerçam essas manifestações. É possível perceber que tais vociferações possuem um caráter implícito de denúncia de uma situação que se dá na educação escolar, mas que reflete as vicissitudes da condição humana atual, do sujeito humano atomizado, desorientado, desvinculado, mas que deseja, mesmo que não o conceba nitidamente, mais do que apenas comunicar a sua não comunicação (Franco, 2002).

Desse modo, entender os meandros através dos quais a grande vedete dos meios de comunicação para as massas - que corroboram o processo de atomização e fragmentação dos sujeitos -, ou seja, a Internet permite que os alunos e os professores se manifestem acerca das relações socioculturais que se dão na sala de aula, a partir da análise da transmutação de suas verbalizações em uma manifestação escrita que conserva em grande parte a estrutura da comunicação oral. Nesse través, diferentemente da narrativa tradicional exposta por Benjamin,

[...] a narração oral no meio digital é uma outra representação, uma organização híbrida em constante mutação. Não é fixa nem autoritária. Em pouco tempo - que tempo? horas? minutos? segundos? - o que verei não será mais a forma inicial, porque ela já foi desmontada e remontada e transformada numa narração que não é mais minha. (Busatto, 2007, p. 117).

A variedade de comunidades virtuais dedicadas ao professor, ao aluno e à escola é enorme, contemplando aspectos positivos e negativos em todos os níveis de ensino. Há desde comunidades sobre o ensino infantil (Professoras de Pré-Escol; Saudade da Pré-Escola) até o de pós-graduação (Meu orientador é ninja; Doutorado gera mais traumas?). Nesse artigo, objetivamos analisar aquelas que dizem respeito às questões relacionadas aos problemas existentes tanto na educação escolar como um todo, como no relacionamento interpessoal entre os envolvidos no processo ensino-aprendizagem.

Vejamos primeiramente algumas manifestações de alunos obtidas no Orkut, o que thes permite - graças às mensagens postadas nas comunidades virtuais - a construção 
ativa de narrativas sobre professores e a escola (Bergmann, 2007, p. 4), as quais, por sua vez, corroboram a imagem negativa que os alunos têm de professores que os humilhariam, os desprezariam e os desencorajariam. Por motivos deontológicos, os nomes dos sujeitos foram trocados e a grafia foi mantida la despeito de desvios ortográficos, de concordância etc). Por essa razão, não utilizamos a marcação [sic].

A comunidade Eu odeio professor frustrado possuía, no início de julho de 2009, mais de sete mil membros, oferecendo um local virtual no qual os alunos podem extravasar suas frustrações decorrentes de exposições vexatórias em sala de aula. Eis alguns trechos de manifestações desses educandos.

A manifestação abaixo foi postada em outubro de 2008:

[... a (professora) de introdução a mineralogia, Pamela Antônia...puta q pariu...pior coisa do mundo é velha mau comida 0.o....ela é tão xata q minha amiga xegho atrasada na hora da prova e ela nem deixou a garota sentar direito no banco, apenas pediu pra garota se retirar e esperar lá fora [ o q eu não sei] ai depois ela xamou a garota de novo....afff". (Orkut, 2008).

Entre os vários comentários postados nos fóruns das comunidades do Orkut sobre a manifestação anterior - a respeito da mesma professora - destacamos o que se segue: “Essa vaca ñ me passa na matéria dela, mas qd faço a msm matéria com outro professor, só tiro nota. FDP espero q tenha um péssimo Natal...solteirona babaca.raiva >_<" (Orkut,2008). É possível perceber as marcas da oralidade nessas transcrições, correlacionadas às abreviações típicas de chats e comunidades virtuais em geral. Além, o sentimento explicitamente expresso na segunda manifestação por meio da palavra "raiva" é seguido pelos caracteres ">_<”, que provavelmente dão ênfase à aversão. Igualmente, podemos apreender nessas manifestações igualmente $o$ arquétipo negativo da figura do professor, associado à figura de um carrasco, presente no texto adorniano Tabus acerca do magistério:

O bom protótipo negativo - estou me referindo apenas a um imaginário de representações que atua no plano inconsciente e não de uma realidade, a não ser que rudimentar - dessa imagerie é o carcereiro, ou ainda melhor, o oficial sargento. Desconheço quanto pode ser elucidativo o fato de que nos séculos XVII e XVIIII se colocava os soldados inválidos como mestres. De qualquer maneira, essa representação popular é bem característica da imago do professor. Aquela palavra tocador de nádegas (Steisstrommler) também tinha ressonâncias soldadescas; talvez represente inconscientemente os professores como aqueles veteranos, como uma espécie de mutilados, como homens que não têm função alguma dentro da vida real. (Adorno, 2001, p. 166). 
Também podemos notar que esse protótipo negativo que abstrai professores e professoras do cotidiano comum também os/as questiona acerca da esfera erótica, já que a referida professora seria alguém não realizado sexualmente, o que contribuiria para a sua "demonização" e atitudes autoritárias (Adorno, 2001, p. 167). Tal negatividade da imagem professoral alcança níveis no mínimo alarmantes em algumas comunidades, como aquela que é intitulada Tomara que o professor morra, que possuía cerca de 60 membros em meados de março de 2011.

Nessa acepção, é necessário observar também comunidades que têm como tema a escola. No que diz respeito às manifestações negativas sobre o processo educacional, podemos mencionar, a título de ilustração, aquela que é denominada ' $\tilde{N}$ mate aula, exploda a escola!!', que em fevereiro de 2011 contava com 802 membros. A imagem oficial dessa comunidade mostra uma explosão nuclear. Entre as enquetes de opinião existentes nessa comunidade, há perguntas como "Vc já fez um plano para explodir sua escola?". Entre os estratagemas oferecidos para a votação que efetivariam a destruição do espaço escolar, há opções como "Ir na cozinha da escola e explodir o botijão!!!”, “Pegava uma lança chamas e tacava fogo em tudo!!!", “Jogava água na tomada pra dar curto circuito!!!" e "Jogava logo um Boeing 747 nessa merda!!!".

No fórum de discussões, podemos citar manifestações como as que se seguem, e que se referem a tentativas frustradas de efetivação de meios violentos de efetivação da ira contra o ambiente escolar, postadas respectivamente nos dias 21 de novembro de 2008 e 4 de janeiro de 2009.

a) eu estava doido pra jogar um rojão no banheiro feminino quando as meninas estiverem lah dentro mais eu amarelei e joguei na coordenação [...]. (Orkut, 2008).

b) eu tentei jogar laxante na caixa d'agua e quase matei o pessoal. (Orkut, 2009).

Recordemos o caso ocorrido em novembro de 2009 na cidade de Juiz de Fora, no qual uma adolescente de 15 anos logrou colocar raticida no bebedouro da sala dos professores de uma escola pública, o que acarretou a internação de vários docentes em um hospital local. Podemos perceber, tanto nas duas manifestações de alunos supramencionadas como no caso da escola estadual mineira, algumas implicações cotidianas no processo fragmentação e reificação das relações humanas. Isso se dá em um cenário no qual pessoas que se dizem frustradas e irritadas com a educação escolar encarnam sua cólera em atos de barbárie e utilizam as comunidades virtuais - que funcionam como meios de aglutinação para o intercâmbio de experiências educacionais que se dão no âmbito de uma formação cultural lesada - como espaços virtuais para uma tentativa de aderência social. Contudo, tal intento os leva ao estabelecimento de novas formas de elos comunitários - distantes dos tradicionais apontados 
por Benjamin - que são assentados, por sua vez, na entropia psicossocial. Por suposto, disso pode resultar um laço cultural efêmero, e, por isso, pobre, conforme afirma Melman (2008).

Por outro lado, a despeito dos aspectos sombrios inerentes a esses intentos comunicacionais no mundo virtual, não se pode negar que os alunos constituem formas privilegiadas de expressão em um contexto educacional que recorrentemente - devido a aspectos pedagógicos, organizacionais e administrativos - lhes é hostil, privando-os da palavra:

Nossos alunos obtêm a informação que desejam, no momento em que a desejam e em qualquer formato em que a desejam. É assim que têm a possibilidade de, "com o mero apertar de um botão", filtrar tudo aquilo que gere um conflito. Ao invés de entrincheirarse diante da angústia da incerteza, a tecnologia lhes outorga a possibilidade de construir suas próprias realidades. (Goldin, 2009, p. 126, tradução nossa).

Nessa orientação, para os fins das lucubrações que tecemos agora, trazemos à discussão uma comunidade formada por professores, na quais temas que dizem respeito a suas vivências com o alunado estão sempre presentes. Dessa forma, é possível perceber as maneiras como esses educadores lucubram sobre suas experiências professorais.

A comunidade Professores de Sociologia possuía no início de junho de 2010 mais de 1.800 membros. No tema Apatia dos alunos, comentários sobre o desinteresse dos educandos em relação aos conteúdos ensinados e a sua indisciplina em sala de aula, além de ponderações sobre os motivos conjunturais que geram tais situações, são recorrentes:

Os alunos, na maioria das vezes, nao se interessam, se peço trabalho eles nao fazem e os q fazem apenas copiam o conteudo da wikipedia. Desafiam, nao sabem o q eh educação. Tem um ou outro q senta na frente, escuta o q digo, só q a apatia dos alunos nao eh um desgosto q só vc passa. 0 q vai acontecer eh q, no futuro, quem souber um pouco de coisa a mais vai nadar de braçada no mercado de trabalho. E nós seremos as cobaias desses futuros medicos, professores, advogados, dessa geração q nao sabe nem o q eh introdução, conclusão e referencias bibliográficas. (Orkut, 2010).

Essa manifestação, além de criticar uma postura bastante comum atualmente, que diz respeito à apropriação indevida de trabalhos acadêmicos na Internet como Cunha (2007) já o apontara, também diz respeito à sensação de desconforto de um professor que se percebe como "uma mera paródia do poder verdadeiro". Nesse caso, Adorno se refere ao funcionário público de casta inferior, cujo poder exercido sobre as crianças em uma escola não se compararia ao poder exercido pelo alto funcionalismo público, 
e tampouco ao exercido pelos profissionais liberais, cujas profissões estão mais submetidas à lógica mercadológica do que a docente (Adorno, 2001, p. 163), ao menos no período em que Adorno escreveu Tabus a respeito do professor. Contudo, é razoável acrescentar que atualmente, na realidade brasileira, esse preconceito persiste. Parcela considerável dos educadores leciona em escolas privadas. Mesmo que gozem de algum status em relação aos seus colegas que atuam nos sistemas públicos de ensino, ainda assim os preconceitos contra a categoria como um todo sobrevivem. Tal desconforto em relação à situação professoral atual mistura-se à imagem extremamente negativa que muitos professores têm acerca de seus alunos e a perspectivas de um futuro sombrio, o que pode ser percebida na manifestação de outra docente no mesmo tópico de debate:

[...] estava na rede pública do Paraná e entrei em uma escola particular, cara, é mil vezes pior. Sabe o que é você entrar numa sala e absolutamente todos os alunos estarem de pé, de costas para você, olhando para a parede e conversando entre si. Você pode arrancar a roupa, subir na mesa, não importa, é uma geração que me assusta por conseguir viver absolutamente centrada em seu único ser, como se o resto do mundo não existisse. Nada importa, apenas o que querem ou o que gostam, são fascistas, racistas homofóbicos, não possuem nenhum respeito por quem não seja dos seus seletos grupinhos, o descaso é tão imenso que tem a pachorra de conversarem no mesmo tom de voz que você está dando aulas, com um colega do outro lado da sala de aula. Fico brava com esta situação? Não, fico chocada e preocupada, acho que esta próxima geração será terrivelmente cruel e egoísta, temo profundamente a sociedade daqui a 20, 30 anos. (Orkut, 2010).

Tal desilusão também pode ser percebida em outra postagem:

Fim da História? Não acredito nessa geração. Creio que nem eles acreditam em si mesmos. Uma vez li a análise de um sociólogo sobre o jovem atual. Ele dizia que esse jovem tem tanto medo do futuro, que o mundo é tão incerto para eles, que preferem viver o hoje como se não fosse existir amanhã. 0 que vcs acham? (Orkut, 2010).

As hipóteses dos professores para o entendimento dessas problemáticas prosseguem, de modo que questões referentes à atomização dos sujeitos, ao individualismo ea o desemprego estrutural se desdobram cada vez mais nessas ponderações:

Agora lendo a frase da Laurindaa lembrei de Moisés que ficou 40 anos no deserto até achar a tal terra prometida que estava ao lado deles, só esperando trocar de geração. Ironias a parte... Zigmound Bauman em seu livro "Vidas despediçadas" fala que os jovens não mais pertencem ao exército de reserva, ele diz que hoje são a sucata desse 
exército.Voltando as ironias, talvez o grande Raulzito cantou certo, “a solução é alugar o Brasil", basta achar um bom negociante...Niilista? Ainda bem que por menor que seja a luz na escuridão, ela sempre é visível. Creio que o mais importante hoje é elaborar projetos e políticas para recuperar a instituição pilar de todas, a família. E apesar disso tudo, ainda há alguns pseudo pós-modernos que negam contra toda tradição. Não sou moralista, vivo eticamente, mas está faltando conceitos morais para essa geração do “tudo posso". Alarmado ainda mais com essa mídia hipócrita e irresponsável que temos, nunca a alienação foi tamanha... (Orkut, 2010).

Outras tentativas de solução para esses problemas são oferecidas a partir de posturas individuais em sala de aula que teriam consequências positivas na totalidade da existência social, conforme afirma outra educadora que se dá conta, inclusive, das imposições do espaço virtual sobre o mundo social:

Mundo da Fantasia. Eu vivo a realidade da escola pública...E sei que os alunos enxergam e respeitam quem realmente se dedica à eles. E mesmo no que vcs dizem ser "bagunça" eles estão aprendendo....Hoje não queiram ensinar com silêncio absoluto, porque essa fase já passou há muito tempo....Vivemos no mundo do hiperlink..... e temos que se empenhar muuuuuito se quisermos ter respostas positivas de nossos alunos.Como eu disse é claro que tenho problemas, mas o resultado que venho obtendo da minha prática tem me dado muita esperança....E eles percebem também a apatia do professor, mesmo quando a gente acha que não temos mais nada a fazer, existe sempre uma idéia nova.Insistam sempre... e transforme tb a realidade nua e cria em uma fantasia de uma escola melhor, pq colocar a culpa nos alunos, no sistema, na direção é sempre mais fácil.... Eu sempre digo que para mudar o mundo começa por nós mesmos... Um trabalho de formiga.... que dará resultado no futuro.... Não desistam... (Orkut, 2010).

Outro tema de discussão do fórum desta comunidade, denominado “Eu tenho aluno evangélico", mostra outras questões que dizem respeito ao processo ensino-aprendizagem, como as que se referem aos estereótipos que os professores constroem acerca de seus educandos:

Gente, tem uma situação que me tira do sério: alunos evangélicos.Toda vez que estou explicando algo e esse assunto, essa visão vai de encontro aos dogmas cristãos lao que o pastor disse no culto), tenho problemas em sala de aula. Isso acontece com vcs?Vcs acreditam que um pastor teve a capacidade de dizer no culto que o desemprego no Brasil e responsabilidade das mulhes porque, desde que elas entraram no mercado de treabalho, roubaram os empregos dos homens... Uma aluna me contou. (Orkut, 2010).

Um docente evangélico se manifesta e procura contemporizar: 
Eu sou evangélico. Oi Grizelda, eu sou evangélico, o que comprova a minha tese de que nem todo sociólogo é ateu, he he he. Bem este problema é comum a todas as religiões, não só ao segmento evangélico, PIS tenho alunos muito católicos, que quando vou falar da 'Ética protestante...' só faltam sair da sala, outos levam na boa, entendendo o que se está discutindo. Agora, o fato é que especialmente entre as camadas menos favorecidas da sociedade, tendem a florescer as doutrinas mais conservadoras e daí, é claro, surgem líderes religiosos sem nenhum conhecimento que só nos dão marretada na cabeça, eh phodda. (Orkut, 2010).

É interessante perceber que a existência de outros temas na comunidade "Professores de Sociologia" que estão presentes em tópicos que ilustram reflexos de questões sexuais que constituem um tabu sexual mal resolvido entre professores e alunos (Adorno, 2001). Na manifestação a seguir, um docente mostra aos outros membros da comunidade uma foto de caráter explicitamente erótico postada na página de recados de sua conta por um aluno que supostamente estaria em situação de "dependência" (reprovado em disciplina curricular) em relação a esse professor. Após isso, esse professor entrou na conta desse aluno, leu seu perfil pessoal, o copiou e o reproduziu na comunidade:

Olha o perfil do animal! Paixões: meu cachorro. Esportes: basquete. Atividades: andar de skt. Livros: q q é isso? Música: Massacration. Avril Lavigne. Programas de tv: Xuxa. Cinema: As descobertas de Rocco. Cozinhas: comida, mui comida. (Orkut, 2010).

Primeiramente ocorreu o constrangimento imposto por um aluno que, de certa forma, desafiou o seu professor, na medida em que intentou romper a "barreira da distância intelectual", o que violaria o tabu que concebe o professor enquanto um ser hierarquicamente superior e distante, sobretudo no âmbito erótico. Tal violação foi sugerida por meio da imposição da imagem de teor erótico na conta pessoal do docente. Por sua vez, esse educador expôs o aluno a uma exposição vexatória no local virtual. A ridicularizar o perfil pessoal que apresenta os gostos pessoais desse aluno (chamado de animal), a tensão entre os sujeitos adquire aspectos complexos, que demandam uma ampla investigação sobre a construção das representações de docentes e discentes acerca de si mesmos e da escola. Representações estas que refletem suas experiências no processo ensino-aprendizagem no mundo contemporâneo de acordo com o referencial teórico apresentado. 


\section{Considerações finais}

As manifestações de sujeitos envolvidos na educação escolar no sítio Orkut permitemnos compreender como os professores e alunos percebem aspectos da condição humana contemporânea - de acordo com as reflexões aqui apresentadas - em seu processo semiformativo pessoal. Isso nos possibilita apreender os modos como os indivíduos entendem e reproduzem as relações sociais, culturais, econômicas que regem o mundo atual a partir de suas manifestações orais captadas no ambiente virtual, as quais, por sua vez, objetivam a imagem desses arrolamentos na escola. A dialogicidade construída cotidianamente na relação professor-aluno é preconizada como condição fundamental da práxis pedagógica pela produção acadêmica em educação, a qual recorrentemente reverbera na elaboração de planos e diretrizes governamentais para a educação formal.

Contudo, em um mundo cada vez mais privado do diálogo vinculador das experiências humanas, no qual o simulacro virtual do mundo real congrega sujeitos desorientados e atomizados, esta dialogicidade aparentemente parece não ter condições subjetivas nem objetivas de ser efetivada, o que é evidenciado pelas manifestações de professores e alunos no Orkut, as quais refletem as experiências pedagógicas desses sujeitos. Por outro lado, trazem à tona um clamor implícito que diz respeito justamente à frustração e ao anseio para que esses sujeitos de algum modo possam experienciar conjuntamente o processo ensino-aprendizagem. Juntamente com o progresso científico sem precedentes na nossa história, uma nova barbárie transpassa todos os aspectos da nossa existência, de modo que a escola reflete o entorpecimento cultural que é metamorfoseado dialeticamente em hedonismo vazio, liquidez e atos de ódio. Ver e entender o abismo que separa as pessoas em um mundo em que as relações sociais são cada vez mais reificadas, e os reflexos desse processo na educação, é fundamental em um momento em que estamos extremamente conectados, mas talvez mais solitários - sob certos aspectos - do que jamais estivemos. 


\section{Referências}

ADORNO, Theodor. Teoria da Semiformação. In: PUCCI, Bruno et al. Teoria Crítica e Inconformismo: novas perspectivas de pesquisa. Campinas: Autores Associados, 2010.

ADORNO, Theodor; HORKHEIMER, Max. Dialética do esclarecimento. Rio de Janeiro: Zahar, 2006.

ADORNO, Theodor. Tabus a respeito do professor. In: PUCCI, Bruno et al. Adorno: o poder educativo do pensamento crítico. Petrópolis: Vozes, 2001.

BAUMAN, Zygmunt. Amor Líquido: Sobre a fragilidade dos laços humanos. Rio de Janeiro: Zahar, 2004.

BENJAMIN, Walter. Obras Escolhidas. São Paulo: Brasiliense, 1996. (v. 1)

BENJAMIN, Walter. Obras Escolhidas. São Paulo: Brasiliense, 1994. (v. 3)

BERGMANN, Leila Mury. "Tomara que o professor falte!": O Orkut e a vida escolar. In: REUNIÃO NACIONAL DA ANPED, 30., 2007, Caxambu. Anais... Caxambu: APNED, 2007. Disponível em <http://cce.udesc.br/titosena/Arquivos/Artigos_textos_sociologia/Orkut.pdf>. Acesso em: 11. abr. 2008. BUSATTO, Cléo. A arte de contar histórias no século XXI: Tradição e Ciberespaço. Petrópolis: Vozes, 2007. COSTA, Berlamino. Estética da violência: Jornalismo e produção de sentidos. Campinas: Autores Associados; Piracicaba: Editora UNIMEP, 2002.

CUNHA, Antônio. Apropriação de trabalhos acadêmicos na Internet: distorções éticas num processo de semiformação. In: ENCONTRO NACIONAL DE PROFESSORES DE JORNALISMO, 10., Goiânia, 2007. Anais... Goiânia: 2007. Disponível em <www.fnpj.org.br/soac/ocs/index.php?cf=1>Acesso em: 22. jul. 2009. DEBORD, Guy. A sociedade do espetáculo. Rio de Janeiro: Contraponto, 1997.

DUPAS, Gilberto. Ética e poder na sociedade da Informação. São Paulo: Editora UNESP, 2001.

FEENBERG, Andrew. Modernity Theory and Technology Studies: Reflections on Bridging the Gap. In: MISA, Thomas et al. Modernity and Technology. Cambridge: MIT Press, 2003.

FORMOSO, Maria; BATISTA, Silva. Indústria Cultural e Ideologia. In: PEDROSO, Leda; BERTONI, Luci. Indústria Cultural e Educação: Reflexões críticas. Araraquara: JM, 2002.

FRANCO, Renato. De Baudelaire ao Bang-Jump. In: PEDROSO, Leda; BERTONI, Luci. Indústria Cultural e Educação. Reflexões críticas. Araraquara: JM, 2002.

GAGNEBIN, Jeanne Marie. História e narração em Walter Benjamin. São Paulo: Editora Perspectiva, 1999.

GOLDIN, Analia. El rol de la escuela y los adolescentes tecnológicos. In: ALMADA, Sonia. Infancidas y Adolescencidas: Nuevos deveníres de la clínica. Córdoba: Jorge Sarmiento, 2009.

LASTÓRIA, Luiz Nabuco. Uma nova economia psíquica ou mutações tópicas? In: DURÃO, Fabio et al. Indústria Cultural hoje. São Paulo: Boitempo, 2008.

LE BRETON, David. Adeus ao corpo. In: NOVAES, Adauto. 0 Homem-Máquina: a Ciência manipula o corpo. São Paulo: Companhia das Letras, 2003.

LENARDUZZI, Víctor; GERZOVICH, Diego; ENTEL, Alícia. Escuela de Frankfurt: razón, arte y libertad. Buenos Aires: Eudeba, 2008.

LE GOFF, Jacques. História e Memória. Campinas: Unicamp, 2003. 
MELMAN, Charles. O homem sem gravidade: Gozar a qualquer preço. Rio de Janeiro: Companhia de Freud, 2008.

OLIVEIRA, Alessandro. Confluências e paradoxos entre tradição e modernidade. Uma análise a partir de ideias de Walter Benjamin. Educação Unisinos, São Leopoldo, Universidade do Vale dos Sinos, v. 1, n. 2, p. 122-132, maio-ago. 2008.

RAMOS-DE-OLIVEIRA, Newton. Reflexões sobre a educação danificada. In: PUCCI, Bruno et al. $A$ Educação Danificada. Petrópolis: Vozes; São Carlos: EDUFSCAR, 1997.

TÜRCKE, Christoph. Sociedade excitada: filosofia da sensação. Campinas: Unicamp, 2010.

ZUIN, Antônio. Seduções e simulacros. Considerações sobre a Indústria Cultural e os Paradigmas da Resistência e da Reprodução em Educação. In: PUCCI, Bruno et al. Teoria Crítica e Educação: A questão da formação cultural na Escola de Frankfurt. Petrópolis: Vozes; São Carlos: EDUFSCAR, 2003.

Recebida $1^{\text {a }}$ versão em abril de 2011.

Aprovada $2^{\mathrm{a}}$ versão em outubro de 2011

Alessandro Eleutério de Oliveira, doutorando em Educação no Programa de Pós-Graduação em Educação na Universidade Federal de São Carlos, mestre em Educação Escolar pela Universidade Estadual Paulista. Integrante do Grupo de Estudos e Pesquisas Teoria Crítica e Educação. Atua na área de Filosofia da Educação. Autor do artigo Reflexões sobre a infância e a Educação Escolar (Revista Querubim, Faculdade de Educação da Universidade Federal Fluminense, 2010). E-mail: academix06ahotmail.com

Antônio Álvaro Soares Zuin, doutor em Educação pela Universidade Estadual de Campinas e estudos de pós-doutorado em Filosofia da Educação pela Universidade de Leipzig. Professor Associado do Departamento de Educação, do Programa de Pós-Graduação em Educação da Universidade Federal de São Carlos e bolsista de produtividade em pesquisa do CNPq. Coordenador do Grupo de Estudos e Pesquisas Teoria Crítica e Educação. Publicações: Adoro odiar meu professor: o aluno entre a ironia e o sarcasmo pedagógico. Campinas: Autores Associados, 2008. E-mail: dazudufscar.br 